\title{
Sevoflurane inhibits the progression of ovarian cancer through down-regulating stanniocalcin 1 (STC1)
}

\author{
Chuanfeng Zhang ${ }^{1,2}$, Baosheng Wang ${ }^{2}$, Xiuqin Wang ${ }^{2}$, Xiugui Sheng ${ }^{2,3^{*}}$ and Yongchun Cui i $^{*}$
}

\begin{abstract}
Background: Ovarian cancer is one of the leading causes of female death worldwide, with a poor prognosis of advanced patients. Sevoflurane, a volatile anesthetic commonly used in clinical operations, has been reported to have anti-cancer activity against some tumors. In the present study, we aimed to investigate the effects of sevoflurane on the progression of ovarian cancer and its potential mechanism.

Methods: The effects of sevoflurane on ovarian cancer cell viability, proliferation, migration, invasion, cell cycle, and apoptosis were determined by functional experiments in vitro. Gelatin zymography assay was performed to examine MMP9 activity. In vivo, sevoflurane was injected into mice of transplantation tumor with SKOV3 cells or with pcDNASTC1 treated SKOV3 cells.

Results: We found that sevoflurane inhibited the viability of SKOV3 and OVCAR3 cells in a dose-dependent manner, and colony formation assay revealed that sevoflurane inhibited ovarian cancer cell colony-formation abilities. Additionally, sevoflurane could induce cell cycle arrest and promote cell apoptosis in SKOV3 and OVCAR3 cells. Moreover, sevoflurane reduced the migration and invasion abilities of SKOV3 and OVCAR3 cells, as well as the MMP-9 activity. Furthermore, sevoflurane down-regulated the expression of stanniocalcin 1 (STC1), and up-regulation of STC1 could reverse the inhibitory effects of sevoflurane on cell proliferation and invasion. In vivo, sevoflurane significantly inhibited the tumor growth, which was be reversed by STC1 overexpression.
\end{abstract}

Conclusion: These data reveal an anti-cancer activity of sevoflurane on the growth and invasion of ovarian cancer, which may be through down-regulating STC1. Sevoflurane may serve as a potential anti-cancer agent in ovarian cancer therapy.

Keywords: Sevoflurane, Ovarian cancer, Stanniocalcin 1, Growth, Invasion, MMP-9

\section{Background}

Ovarian cancer is a highly lethal gynecological malignancy and is one of the leading causes of female death, with nearly 239,000 new cases and 152,000 deaths worldwide each year [1]. According to statistics, a woman's lifetime risk of ovarian cancer is $1 / 75$, and the probability of dying from ovarian cancer is $1 / 100$ [2]. What is more

\footnotetext{
*Correspondence: shengxiugui@163.com; cyc0001@126.com

${ }^{2}$ Shandong Cancer Hospital and Institute, Shandong First Medical University and Shandong Academy of Medical Sciences, Jinan 250117, China

Full list of author information is available at the end of the article
}

distressing is that most patients are in advanced stage at the time of diagnosis, accompanied by local or distant metastasis, leading to poor prognosis. The overall 5-year relative survival rate of ovarian cancer patients worldwide is generally between $30 \%$ and $40 \%$ [3]. The 5 -year survival rate of advanced patients is only $29 \%$, while that of early patients is $93 \%[2,4]$. Although the treatment strategies and surgical techniques have been significantly improved, the prognosis of ovarian cancer remains unsatisfactory. The main causes of high mortality and poor prognosis of ovarian cancer are the lack of early diagnosis and resistance to chemotherapy $[5,6]$. Therefore, it is

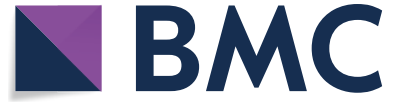

(c) The Author(s) 2019. This article is licensed under a Creative Commons Attribution 4.0 International License, which permits use, sharing, adaptation, distribution and reproduction in any medium or format, as long as you give appropriate credit to the original author(s) and the source, provide a link to the Creative Commons licence, and indicate if changes were made. The images or other third party material in this article are included in the article's Creative Commons licence, unless indicated otherwise in a credit line to the material. If material is not included in the article's Creative Commons licence and your intended use is not permitted by statutory regulation or exceeds the permitted use, you will need to obtain permission directly from the copyright holder. To view a copy of this licence, visit http://creativeco mmons.org/licenses/by/4.0/. The Creative Commons Public Domain Dedication waiver (http://creativecommons.org/publicdomain/ zero/1.0/) applies to the data made available in this article, unless otherwise stated in a credit line to the data. 
necessary to find new targeted agents and strategies for ovarian cancer.

It is well known that surgical resection of tumors is an important method of cancer treatment. Increasing evidences show that anesthetics used in surgical resection also have certain non-anesthetic physiologic effects, which can affect the invasion and migration abilities of tumor cells $[7,8]$. Sevoflurane is a volatile anesthetic commonly used in clinical operations. It has been reported that sevoflurane can inhibit the proliferation of colon cancer, laryngeal cancer cells $[9,10]$ and head and neck squamous cell carcinoma [11], and decrease the migration and invasion abilities of lung cancer $[12,13]$ and glioma cells $[14,15]$. These studies reveal an antitumor activity of sevoflurane, suggesting that sevoflurane may be used as a potential target agent for treatment of cancer. However, little is known about the effects of sevoflurane on the proliferation and invasion of ovarian cancer.

In the present study, for the first time, we investigated the effects of sevoflurane on the proliferation and invasion of ovarian cancer cells. Moreover, we revealed the molecular mechanism of sevoflurane underlying its antitumor activity in ovarian cancer cells.

\section{Materials and methods Cell culture and treatment}

The human ovarian cancer cell lines SKOV3 and OVCAR3 were obtained from the Cell Bank of Chinese Academy of Sciences (Shanghai, China). Cells were routinely grown in DMEM medium supplemented with $10 \%$ fetal bovine serum (FBS), $100 \mathrm{U} / \mathrm{mL}$ penicillin (SigmaAldrich, Germany) and $0.1 \mathrm{mg} / \mathrm{mL}$ streptomycin (SigmaAldrich). SKOV3 and OVCAR3 cells were cultured in medium supplemented with sevoflurane (Maruishi Pharmaceutical, Japan) in vitro, and DMSO was used as negative control (NC). The STC1 cDNA sequence was cloned into the pcDNA3.1 vector to construct the STC1 expressing plasmid. Cells were transfected with pcDNA3.1STC1 vector using Lipofectamine 2000 (Invitrogen, USA) to up-regulate the expression of STC1, and the control group was transfected with an empty vector.

\section{CCK8 assay}

Cells were exposed to different concentration of sevoflurane $(0.5,1,1.5,2,2.5,3,4,5$, and $6 \%$ for SKOV3 cells; $0.5,1,1.5,2,2.5,3,3.5,4,4.5,5,5.5,6,6.5,8$ and $10 \%$ for OVCAR3 cells) in a 96-well plate at $37^{\circ} \mathrm{C}$ for $24 \mathrm{~h}$. With an addition of cell Counting Kit-8 reagent $(10 \mu \mathrm{L} /$ well; CCK8; Beijing Solarbio Science \& Technology, Beijing, China), cells were cultured for $90 \mathrm{~min}$ at $37^{\circ} \mathrm{C}$. The absorbance was measured at $450 \mathrm{~nm}$ with a Bio-Rad microplate reader (Bio-Rad Laboratories, USA).

\section{Colony formation assay}

SKOV3 and OVCAR3 cells were treated with sevoflurane for $24 \mathrm{~h}$, and grown in $35 \mathrm{~mm}$-plates at a density of $5 \times 10^{2} /$ well and cultured in DMEM at $37{ }^{\circ} \mathrm{C}$ for about 1 week until the visible colonies were formed. Then, the medium was removed and the colonies were fixed with $4 \%$ paraformaldehyde for $30 \mathrm{~min}$ followed by staining with $0.1 \%$ crystal violet for $30 \mathrm{~min}$. The colonies were counted and photographed.

\section{Cell cycle analysis}

Flow cytometry was performed to assess the effect of sevoflurane on cell cycle distribution. After $24 \mathrm{~h}$ treatment with sevoflurane at $37^{\circ} \mathrm{C}$, cells were collected and fixed with $70 \%$ pre-cooling ethanol at $-20{ }^{\circ} \mathrm{C}$ overnight. After that, cells were stained with propidium iodide (PI) for $30 \mathrm{~min}$ in the dark, the cell cycle was analyzed using a flow cytometer (BD FACSC anto II, BD Biosciences, USA). The data was analyzed with BD FACSDiva software (BD Bioscience).

\section{Cell apoptosis analysis}

Annexin V-FITC/PI kit (BD Bioscience) was performed to examine cell apoptosis. SKOV3 and OVCAR3 cells were treated with sevoflurane for $24 \mathrm{~h}$, and cells were collected and stained with $5 \mu \mathrm{L}$ of Annexin V-FITC for $5 \mathrm{~min}$ in the dark and stained with $10 \mu \mathrm{L}$ of PI at room temperature. The rate of apoptosis in each sample was analyzed using a flow cytometer (BD FACSC anto II) and calculated by BD FACSDiva software.

\section{Western blot}

After being treated with sevoflurane for $48 \mathrm{~h}$, cells were harvested and lysed with RIPA Lysis Buffer (CWBIO, Beijing, China) to extract protein. Then, $20 \mu \mathrm{g}$ protein of each sample was electrophoresed on 10\% SDS-PAGE gel, and transferred onto polyvinylidene fluoride membrane (PVDF; Millipore, Billerica, MA, USA). Subsequently, the members were blocked with $5 \%$ dried skimmed milk for $1 \mathrm{~h}$ followed by incubation with primary antibodies (dilution, 1:1000; Proteintech Group, IL, USA) at $4{ }^{\circ} \mathrm{C}$ overnight. After labelling with horseradish peroxidase (HRP)-conjugated secondary antibodies (dilution, 1:3000; Proteintech Group) for $1 \mathrm{~h}$, the signals were visualized using an Enhanced Chemiluminescence kit (CWBIO). $\beta$-tubulin was used as endogenous control, and the relative expression of proteins were normalized to $\mathrm{NC}$.

\section{Wound-healing assay}

A wound-healing assay was performed to assess cell migration ability. About $5 \times 10^{5}$ cells per well were 
grown in a 6-well plate and cultured for $24 \mathrm{~h}$ at $37{ }^{\circ} \mathrm{C}$. Subsequently, cells were scraped with pipette tips to generate a straight-line "wound". After then cells were treated with sevoflurane for $24 \mathrm{~h}$ at $37{ }^{\circ} \mathrm{C}$. Cells were photographed and the wound closure was analyzed quantitatively using ImageJ software (National Institutes of Health, USA).

\section{Transwell assay}

Cell migration and invasion abilities were examined using the Transwell assay. Transwell chamber (Millipore, MA, USA) were coated with Matrigel (BD Bioscience, CA, USA) for cell invasion assay. SKOV3 and OVCAR3 cells were treated with sevoflurane for $24 \mathrm{~h}$ and suspended in serum-free medium at $1 \times 10^{6}$ cells $/ \mathrm{mL}$. $100 \mu \mathrm{L}$ of cell suspensions were added into the upper inserts, and $700 \mu \mathrm{L}$ of complete medium supplemented with $20 \%$ FBS was added to the lower chamber as the chemo attractant. After incubation for $24 \mathrm{~h}$, the invaded cells were fixed with $4 \%$ paraformaldehyde for 30 min prior to stain with $0.1 \%$ crystal violet for $20 \mathrm{~min}$. The migration assay was performed in the same manner as the invasion assay, except that Matrigel was not required. The invaded and migrated cells were imaged (magnification, 100×) and counted under the light microscope.

\section{Gelatin zymography assay}

Gelatin zymography assay was used to examine the effect of sevoflurane on MMP-9 activity. SKOV3 and OVCAR3 cells were cultured for $48 \mathrm{~h}$ at $37{ }^{\circ} \mathrm{C}$ in serum-free medium supplemented with sevoflurane. After that, cell culture supernatants were collected and electrophoresed on a $10 \%$ SDS-PAGE containing $0.5 \mathrm{mg} / \mathrm{mL}$ gelatin. The gel was eluted two times in the eluent (2.5\%Triton X-100, $50 \mathrm{mM}$ Tris- $\mathrm{HCl}, 5 \mathrm{Mm} \mathrm{CaCl}_{2}, \mathrm{pH} 7.6$ ), then washed in the rinsing solution without Triton $\mathrm{X}-100$ and incubated with the incubation solution $(50 \mathrm{mM}$ Tris- $\mathrm{HCl}, 5 \mathrm{Mm}$ $\mathrm{CaCl}_{2}, 0.02 \%$ Brij-35, pH 7.6) for $42 \mathrm{~h}$ at $37^{\circ} \mathrm{C}$. After incubation, the gel was stained with $0.05 \%$ Coomassie Blue $\mathrm{R} 250$ for $4 \mathrm{~h}$ prior to decolorization at room temperature. The band of MMP-9 was scanned using an Image Scanner (Amersham, USA) and analyzed by ImageQuant TL V2003 software.

\section{Animal model}

The animal experiments in this study were performed according to the guidelines for the care and use of laboratory animals and approved by Shandong Cancer Hospital Affiliated to Shandong University. The transplanted tumor model was established with reference to Zhang et al. [16]. SKOV3 cells were prepared with or without transfection of pcDNA3.1-STC1. Eighteen BALB/c-Nude mice (female, 4-6 weeks old; Shanghai SLAC Laboratory
Animal Co., Ltd.) were randomly divided into three groups: Group 1 and Group 2 were injected subcutaneously with $5 \times 10^{5}$ SKOV3 cells into the right armpit of mice; Group 3: mice were injected with SKOV3 cells transfected with pcDNA3.1-STC1. After 7 days of feeding, we dissolved the sevoflurane $(50 \mathrm{mg} / \mathrm{kg})$ in $0.5 \mathrm{~mL}$ of soybean oil and injected into Group 2 and Group 3 mice for 3 weeks (once a day), Group 1 was injected with the same volume of soybean oil as control. Tumor size was measured every 4 days, and the tumor size was measured after mice sacrifice.

\section{Statistical analysis}

All data were performed as mean $\pm S D$ from triplicate independent experiments and statistically analyzed using GraphPad Prism 7.0 (GraphPad, CA, USA). Differences between groups were analyzed using the student's t test or one-way ANOVA, and $\mathrm{P}<0.05$ was considered statistically significant.

\section{Results \\ Sevoflurane inhibits the proliferation of ovarian cancer cells}

To investigate the cytotoxicity of sevoflurane to ovarian cancer, SKOV3 and OVCAR3 cells were treated with different concentration of sevoflurane. As shown in Fig. 1a, after $24 \mathrm{~h}$ of treatment, sevoflurane inhibited cell viability in a dose-dependent manner in SKOV3 cells, and the $\mathrm{IC}_{50}$ of sevoflurane for SKOV3 cells was $1.598 \%$. Similarly, a decrease in cell viability caused by different concentrations of sevoflurane was observed in OVCAR3 cells, whereas in OVCAR3 cells, the $\mathrm{IC}_{50}$ of sevoflurane was $1.350 \%$ (Fig. 1b). Therefore, in the following experiments, SKOV3 cells were treated with $0.95 \%$ of sevoflurane, and OVCAR3 cells were treated with $0.8 \%$ of sevoflurane for its appropriate effect. The colony formation assay was performed to further assess the growth-inhibitory effect of sevoflurane on ovarian cancer cells. As expected, in comparison with NC group, sevoflurane significantly suppressed colony-formation abilities of SKOV3 and OVCAR3 cells (Fig. 1c).

\section{Sevoflurane induces cell cycle arrest in ovarian cancer cells} Given the inhibitory effect of sevoflurane on cell proliferation of ovarian cancer, we examined its effect on cell cycle distribution by flow cytometry. The results showed that the percentage of cells in the G0/G1 phase was significantly increased in SKOV3 cells exposed to sevoflurane, and the proportions of cells in the $\mathrm{S}$ phase was decreased compared with NC group (Fig. 2a). In OVCAR3 cells, the results were similar, and the proportion of cells in the G0/G1 phase was also significantly increased, and the proportions of cells in the $S$ 

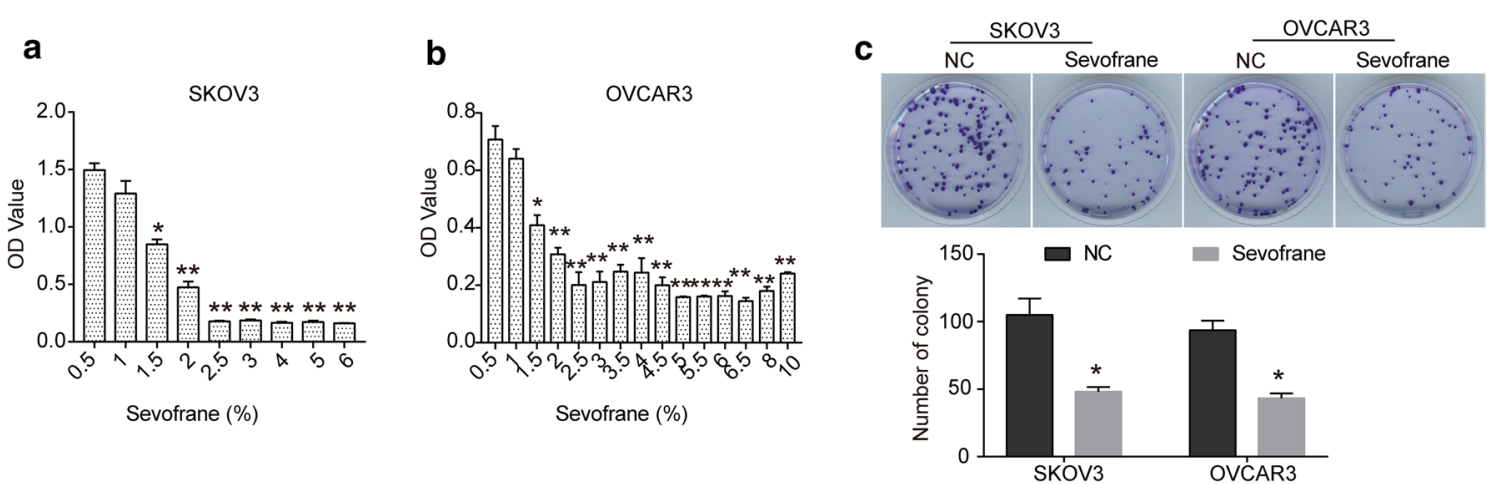

Fig. 1 Sevoflurane inhibits the viability and colony-formation ability of ovarian cancer cells. $\mathbf{a}$, b SKOV3 (a) and OVCAR3 (b) cells were treated with different concentrations of sevoflurane for $24 \mathrm{~h}$, CCK8 assay was performed to examine cell viability. c After being treated with sevoflurane, colony formation assay was performed. The data were expressed as the mean \pm SD from three independent experiments. ${ }^{*} P<0.05$, ${ }^{* *} P<0.01 \mathrm{vs}$. the negative control group

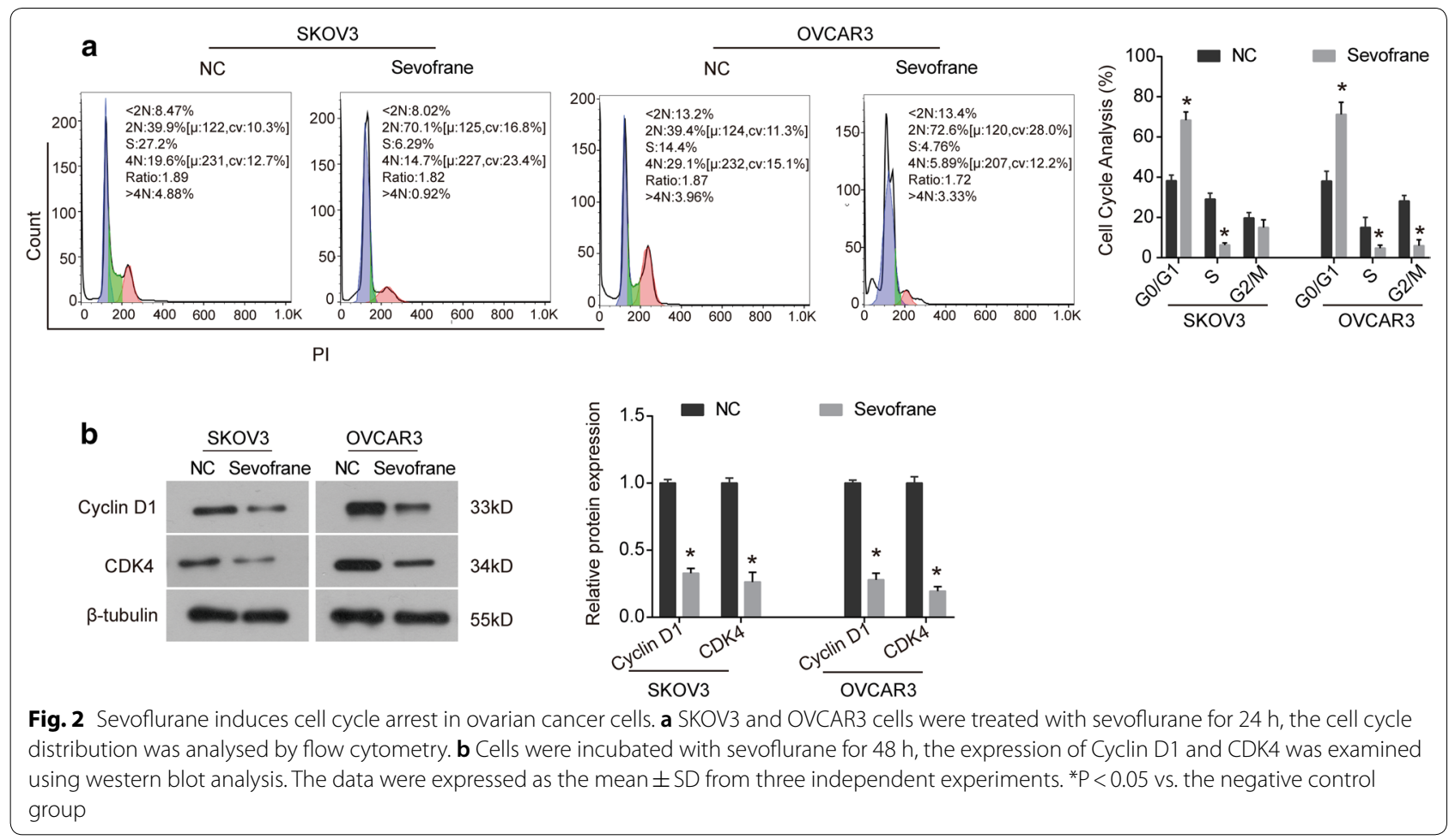

and G2/M phases were both decreased (Fig. 2a). Moreover, we examined the expression of cell cycle-related proteins using western blot analysis. Our data showed that sevoflurane caused a significant decrease in the expression level of Cyclin D1 and CDK4 in SKOV3 and OVCAR3 cells (Fig. 2b). Collectively, these data suggest that sevoflurane could induce cell cycle arrest at the G0/G1 phase in SKOV3 and OVCAR3 cells via downregulating the expression of Cyclin D1 and CDK4.
Sevoflurane promotes cell apoptosis in ovarian cancer cells The effect of sevoflurane on cell apoptosis in ovarian cancer was evaluated using PI-Annexin V double staining. Our data showed that, in comparison with NC group, sevoflurane obviously promoted the rate of apoptosis in both SKOV3 and OVCAR3 cells (Fig. 3a). Changes in expression levels of apoptosis-related proteins after exposure to sevoflurane were examined by western blot to further investigate the mechanism 

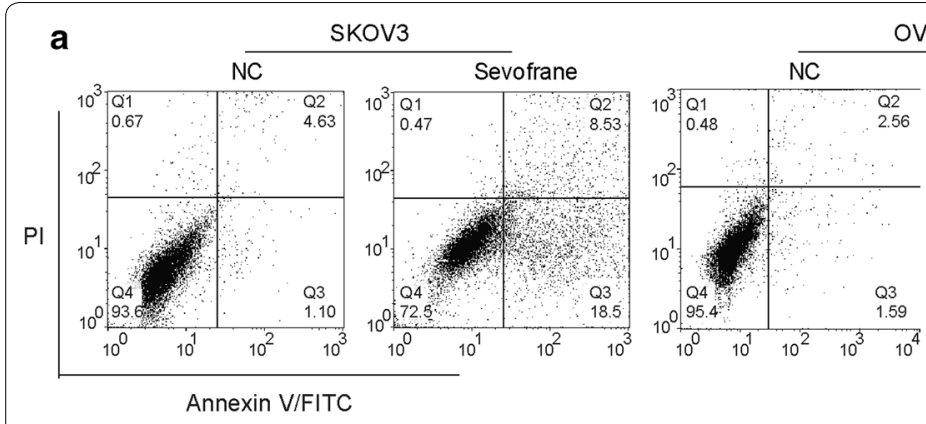

OVCAR3
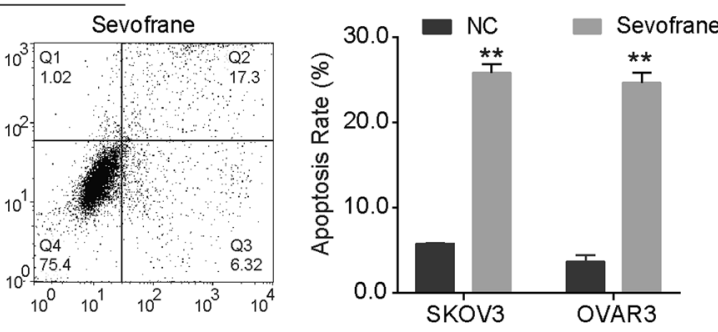

b
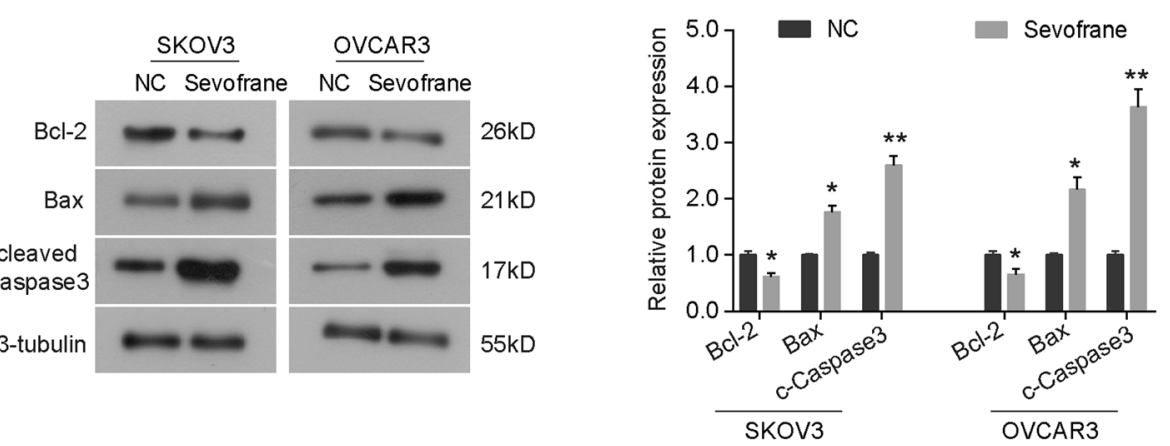

Fig. 3 Sevoflurane promotes cell apoptosis in ovarian cancer cells. a Flow cytometry was used to detect the rate of apoptosis in SKOV3 and OVCAR3 cells exposed to sevoflurane for $24 \mathrm{~h}$. b After $48 \mathrm{~h}$ of incubation with sevoflurane, the expression of apoptosis-related proteins (Bcl-2, Bax and cleaved Caspase3) was detect by western blot analysis. The data were expressed as the mean \pm SD from three independent experiments. ${ }^{*} \mathrm{P}<0.05,{ }^{* *} \mathrm{P}<0.01$ vs. the negative control group

underlying the inducted apoptosis. As indicated in Fig. 3b, the expression of anti-apoptosis protein Bcl-2 was significantly down-regulated by sevoflurane in both SKOV3 and OVCAR3 cells, while the expression of pro-apoptosis proteins Bax and cleaved Caspase 3 was up-regulated in sevoflurane-treated group (Fig. 3b). These data indicate that sevoflurane induces cell apoptosis in ovarian cancer cells through regulating the $\mathrm{Bcl}-2 / \mathrm{Bax}$ axis and Caspase activity.

\section{Sevoflurane inhibits the migration and invasion abilities of ovarian cancer cells}

As shown in Fig. 4a, SKOV3 and OVCAR3 cells treated with sevoflurane exhibited significant depression in migration compared with NC group. Additionally, the Transwell migration assay reveled similar results that sevoflurane significantly inhibited migration ability of SKOV3 and OVCAR3 cells (Fig. 4b). Moreover, sevoflurane inhibited the invasion ability of SKOV3 and OVCAR3 cells that the number of invading cells in the sevoflurane-treated group was much lower compared with NC group (Fig. 4c). Taken together, these results reveal an anti-motility activity of sevoflurane in ovarian cancer.

\section{Sevoflurane inhibits the Akt/mTOR/p70S6k signaling pathway and MMP-9 activity}

In view of the pivotal role of Akt/mTOR signaling pathway in the regulation of cell proliferation and survival, changes in the expression of key components of Akt/ mTOR pathway were detected under sevoflurane treatment. As indicated by Western blot, the expression of total Akt and mTOR did not been affected by sevoflurane in both SKOV3 and OVCAR3 cells, while the phosphorylation levels of Akt (p-Akt) and mTOR (p-mTOR) were significantly decreased (Fig. 5a). The expression of p70S6k was also down-regulated by sevoflurane treatment (Fig. 5a). In addition, we found that the activity of MMP-9, a key regulator involved in invasion process, was significantly diminished in SKOV3 and OVCAR3 cells treated with sevoflurane (Fig. 5b).

\section{Sevoflurane inhibits cell proliferation and invasion by down-regulating stanniocalcin 1 (STC1)}

To further elucidate the potential mechanisms underlying the anti- growth and -invasion activity of sevoflurane in ovarian cancer, RNA-Seq by PossionDis was performed to determine significantly differential expressed genes ( $\mid \log _{2}$ fold change $\mid>1$ and $Q$ value $<0.001)$ in sevoflurane-treated cells. The data 


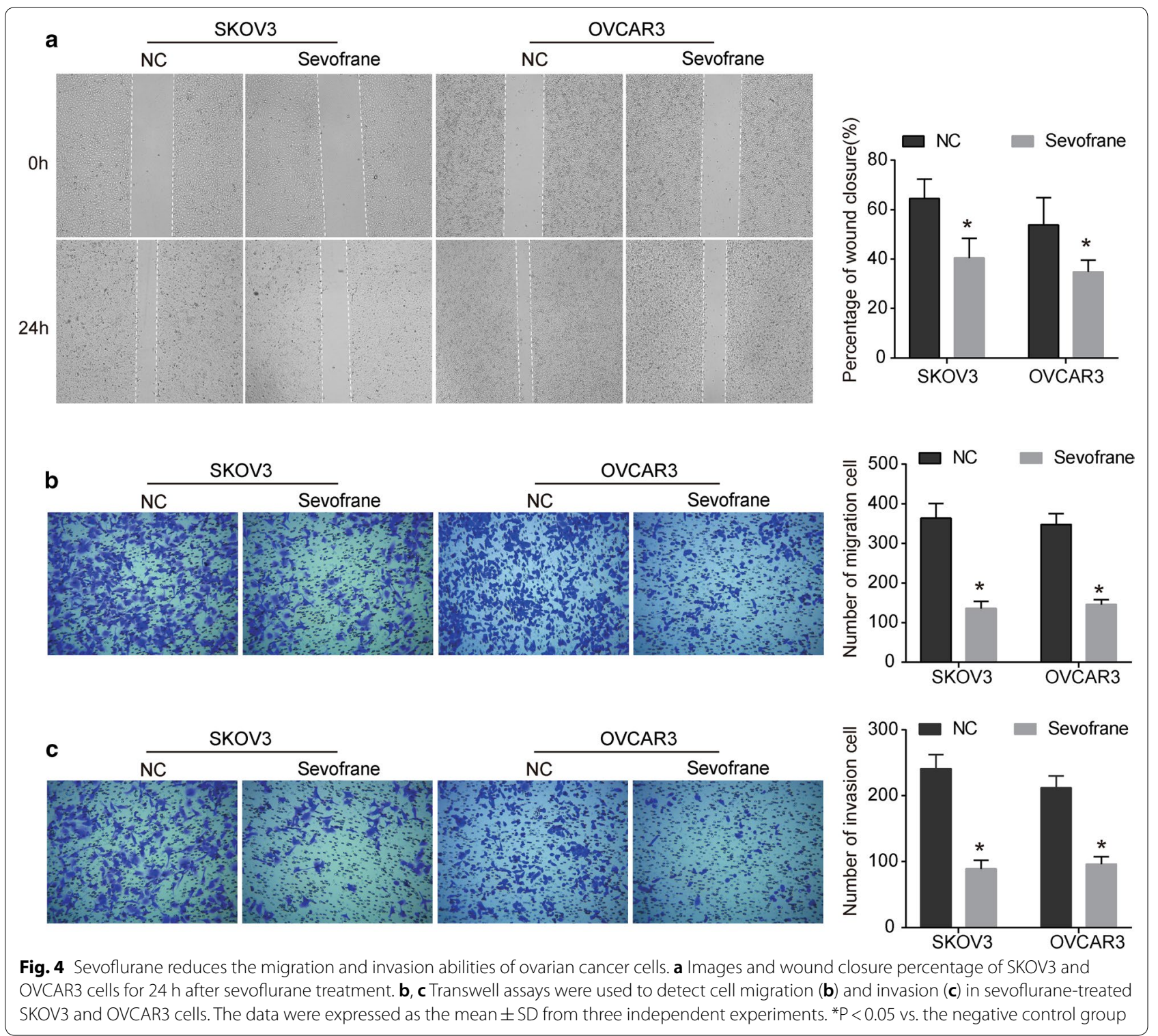

showed that the expression of STC1 was significantly down-regulated by sevoflurane, which was further confirmed by the results of western blot (Fig. 6a). In addition, transfection with pcDNA3.1-STC1 reversed the inhibitory effect of sevoflurane on the expression of STC1 in both SKOV3 and OVCAR3 cells compared to those after sevoflurane treatment alone (Fig. 6a). Therefore, STC1 might be a target gene for sevoflurane.

STC1 has been revealed to be up-regulated in ovarian cancer and involved in tumor progression [17]. We suspected that STC1 may be involved the effect of sevoflurane on proliferation, migration and invasion of ovarian cancer cells. Our data showed that up-regulation of STC1 reversed the suppression in cell viability caused by sevoflurane in a time-dependent manner in SKOV3 cells (Fig. 6b). Similar results were observed in OVCAR3 cells (Fig. 6c). Next, a Transwell assay was used to assess cell migration and invasion. As shown in Fig. 6d, e, the depression in the migration ability induced by sevoflurane was significantly rescued by the up-regulation of STC1 in both SKOV3 and OVCAR3 cells. Moreover, the inhibitory effect of sevoflurane on cell invasion was also reversed by the presence of STC1 in SKOV3 and OVCAR3 cells (Fig. 6d, e). Furthermore, up-regulation of STC1 also reversed the activity of MMP-9 in sevoflurane-treated cells (Fig. 6f). 


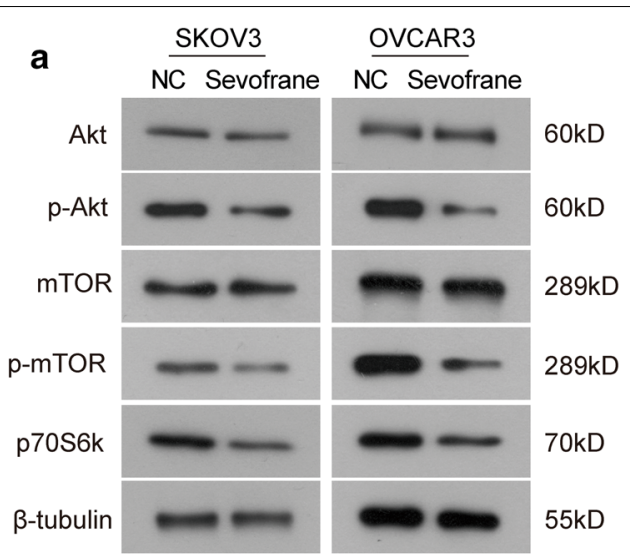

b

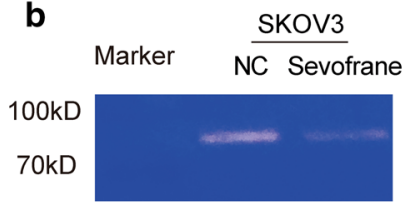

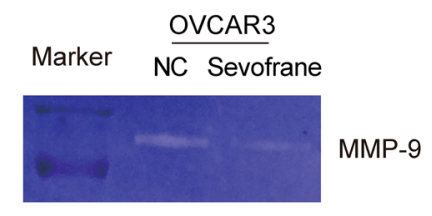

Fig. 5 Sevoflurane inhibits the Akt/mTOR signaling pathway and MMP-9 activity. a SKOV3 and OVCAR3 cells were treated with sevoflurane for $48 \mathrm{~h}$, the effects of sevoflurane on Akt/mTOR signaling pathway were analyzed by western blot assay. $\mathbf{b}$ Gelatin zymography assay was used to examine the effect of sevoflurane on MMP-9 activity. The data were expressed as the mean \pm SD from three independent experiments. ${ }^{*}<<0.05$ vs. the negative control group

\section{Sevoflurane reduces the growth of tumor by regulating STC1 in vivo}

The model of transplantation tumor of SKOV3 cells in nude mice was established. As shown in Fig. 7a, b, we observed that the injection of $50 \mathrm{ng} / \mathrm{kg}$ sevoflurane significantly reduced the tumor volume compared with the NC group, while the anti-tumor effect of sevoflurane could be partly reversed by up-regulation of STC1.

\section{Discussion}

It has been reported that anesthesia and anesthesia techniques may influence the progression of cancer after surgery $[7,18]$. Sevoflurane has been revealed to inhibit cell migration and invasion in lung cancer and glioma cells [12-15]. In this study, we firstly demonstrated that sevoflurane significantly inhibited the proliferation of ovarian cancer SKOV3 and OVCAR3 cells in a dose-dependent manner, and reduced cell migration and invasion abilities, as well as inhibited tumor growth in vivo. Moreover, treatment with sevoflurane induced cell cycle arrest and promoted cell apoptosis in SKOV3 and OVCAR3 cells. Collectively, these results suggest that sevoflurane might serve as an anti-tumor agent for therapy of ovarian cancer.
It is well known that inducing cell cycle arrest and promoting apoptosis are two effective approaches to inhibit cell growth. Normal cell cycle process is the key mechanism for cell proliferation, and cancer cells are commonly characterized by cell cycle dysregulation [19, 20]. Blocking cell cycle is also one of the mechanisms of many anti-cancer agents [21-23]. It has been reported that sevoflurane induces cell cycle arrest at G1 phase in breast cancer cells [24]. In our study, we found that the proportion of cells in the G0/G1 phase was significantly increased in sevoflurane-treated group, the proportion in the $\mathrm{S}$ phase was accordingly decreased (Fig. 2), denoting a remarked cell cycle arrest at G0/G1 phase induced by sevoflurane in ovarian cancer cells, which was consistent with previous study [24]. Moreover, the expression of Cyclin D1 and CDK4, the key regulators in promoting cell transition from G1 phase to S phase, was significantly down-regulated by sevoflurane. Collectively, sevoflurane arrests cell cycle in the G0/G1 phase through down-regulating Cyclin D1/CDK4, resulting in the inhibition of cell proliferation.

Promoting tumor cell apoptosis is one of the important features of cytotoxic anti-tumor agents [25-27]. In the current study, our results from flow cytometry suggested that sevoflurane promoted the rate of apoptosis 


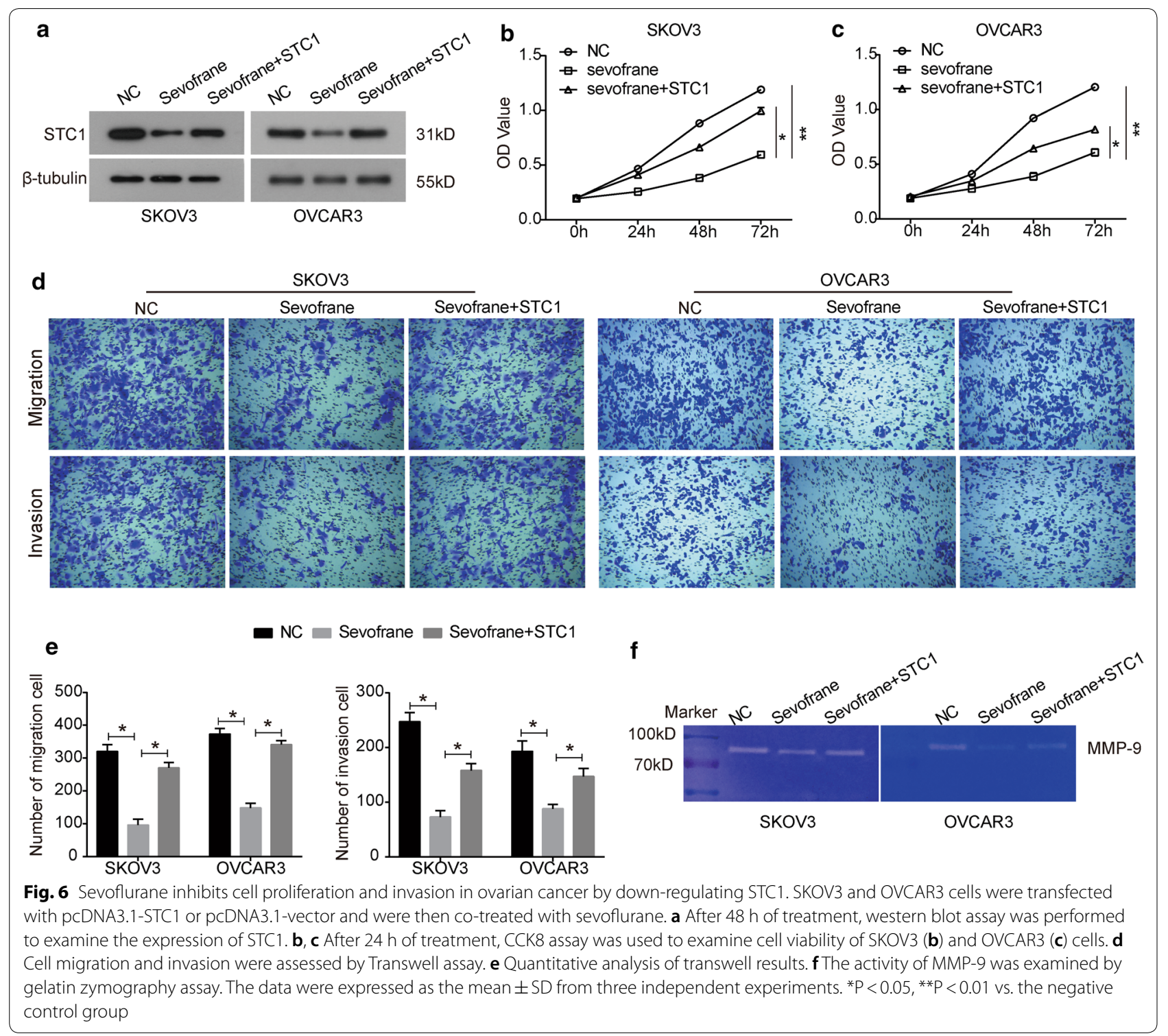

in SKOV3 and OVCAR3 cells (Fig. 3). Bcl-2 and caspase families are key regulators involved in apoptosis process $[27,28]$. We observed that the expression of Bcl-2 was significantly up-regulated by sevoflurane, whereas the expression of Bax and cleaved Caspase3 was down-regulated, indicating that sevoflurane promotes cell apoptosis in ovarian cancer through regulating the Bcl-2/Bax axis and Caspase cascade. Yang et al. [11] report that sevoflurane induces apoptosis and suppresses the expression of Bcl-2 in head and neck cancer cell lines $\mathrm{FaDu}$ and $\mathrm{CAL}-27$. Taken together, these results indicates that sevoflurane may exert its antigrowth effect through triggering cell cycle arrest and inducing apoptosis in ovarian cancer.
The Akt/mTOR signaling pathway has been implicated in cancer development, and is frequently aberrant activated in cancers. Akt/mTOR signaling pathway has been proved to play pivotal roles in the regulation of cell proliferation, cell cycle and apoptosis [29, 30]. The suppression of the Akt/mTOR signaling has been shown to be an effective strategy to the treatment of cancers and is the mechanism for the activity of many anti-tumor agents $[31,32]$. Our study demonstrated that sevoflurane could reduce the phosphorylation of Akt and mTOR in SKOV3 and OVCAR3 cells (Fig. 5). Additionally, the expression of p70S6k, the target of mTOR, was accordingly downregulated by sevoflurane. In head and neck cancer cells, sevoflurane is revealed to inhibit the phosphorylation of 

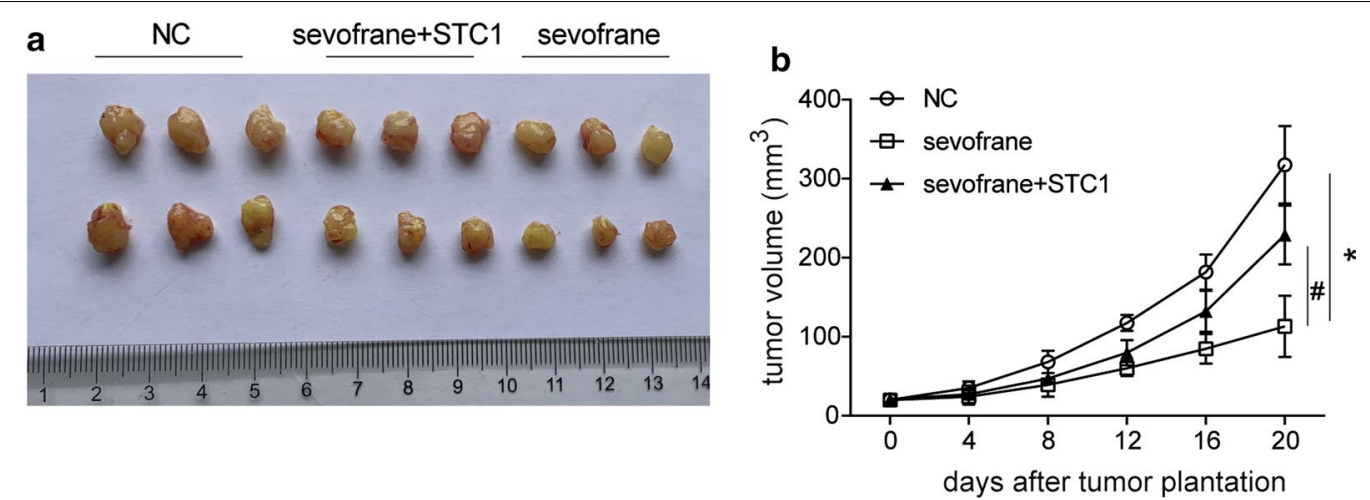

Fig. 7 Sevoflurane reduces tumor volume in SKOV3 cell transplanted tumor mice. SKOV3 cells with or without transfection of pCDNA3.1-STC1 were injected into the nude mice for 7 days. Mice were injected of $50 \mathrm{ng} / \mathrm{kg}$ sevoflurane (dissolved into $0.5 \mathrm{~mL}$ soybean oil) or $0.5 \mathrm{~mL}$ soybean oil for 3 weeks. After the mice were sacrificed, the tumor was dissected (a) and the tumor volume was measured (b). * $\mathrm{P}<0.05$ vs. the negative control group, ${ }^{\#} P<0.05$ vs. the sevoflurane treatment

Akt [11], which is consistent with our results in ovarian cancer. Liang et al. [12] reveal that sevoflurane inhibits the migration and invasion abilities of A549 cells through inhibiting p38 MAPK signaling pathway and the activities of MMP-2 and MMP-9. Hurmath et al. [15] find that sevoflurane suppresses the migration of U87MG glioma cells by attenuating the activity of MMP-2. Herein, we observed that sevoflurane significantly attenuated the activity of MMP-9 in SKOV3 and OVCAR3 cells. In combination with the above studies, we suggest that the Akt/ mTOR signaling pathway and MMP-9 might be implicated in the anti-tumor activity of sevoflurane.

Further assays were performed to investigate the molecular mechanism underlying the anti-tumor activity of sevoflurane in ovarian cancer. From high-throughput sequencing and western blot analysis, we found that the expression of STC1 was significantly down-regulated in sevoflurane-treated cells. STC1, a secreted glycoprotein, has been reported to be involved in several pathologies, including angiogenesis and inflammation [33-35]. Emerging evidences have revealed that STC1 is implicated in carcinogenesis and the progression of mangy types of cancer, including but not limited to colorectal, breast, hepatocellular carcinoma, cervical, and ovarian cancer [17, 36-39]. Liu et al. [17] has reported that STC1 is up-regulated in ovarian cancer tissues, cell lines and serum from patients, its overexpression could promote cell proliferation, migration and tumor growth in mice model. Moreover, knockdown of STC1 could arrest cell cycle in G0/G1 phase and promote apoptosis in SKOV3 cells [17], suggesting an oncogenic role of STC1 in ovarian cancer. In the current study, the suppression in cell proliferation, migration and invasion caused by sevoflurane was significantly reversed by the up-regulation of STC1 in SKOV3 and OVCAR3 cells, as well as MMP-9 activity (Fig. 6). Further, we observed that the inhibition of sevoflurane in tumor growth was reserved by up-regulation of STC1. These results indicate that sevoflurane may exert the anti-tumor activity through targeting STC1 in ovarian cancer.

\section{Conclusion}

In summary, for the first time, our data demonstrate sevoflurane inhibits cell proliferation, migration and invasion and induces cell cycle arrest and apoptosis in ovarian cancer cells through targeting STC1. The Akt/ mTOR signaling pathway may be implicated in the antitumor activity of sevoflurane. This study provides evidence that sevoflurane might represent a potential novel targeted agent in the treatment of ovarian cancer. Further study is needed to investigate the anti-tumor activity of sevoflurane in mice model and its deeper molecular mechanism.

\section{Abbreviations}

Akt: protein kinase B; CCK8: cell counting kit-8 reagent; FBS: fetal bovine serum; GEPIA: Gene Expression Profiling Interactive Analysis; mTOR: mammalian target of rapamycin; STC1: stanniocalcin 1.

\section{Acknowledgements}

Not applicable.

\section{Authors' contributions}

Conception and design, acquisition of data, or analysis and interpretation of data: all authors. Drafting the article or revising it critically for important intellectual content: $C Z, X S$ and $Y C$. Final approval of the version to be published: all authors. Agreement to be accountable for all aspects of the work in ensuring that questions related to the accuracy or integrity of any part of the work are appropriately investigated and resolved: all authors. All authors read and approved the final manuscript.

Funding

No. 


\section{Availability of data and materials}

The data supporting the conclusions of this paper are included within the manuscript.

\section{Ethics approval and consent to participate}

Not applicable.

\section{Consent for publication}

All the authors agree to the publication clause.

\section{Competing interests}

The authors declare that they have no competing interests.

\section{Author details \\ ${ }^{1}$ Shandong Cancer Hospital Affiliated to Shandong University, Jinan 250117, China. ${ }^{2}$ Shandong Cancer Hospital and Institute, Shandong First Medical University and Shandong Academy of Medical Sciences, Jinan 250117, China. ${ }^{3}$ National Cancer Center/National Clinical Research Center for Cancer/Can- cer Hospital and Shenzhen Hospital, Chinese Academy of Medical Sciences and Peking Union Medical College, Shenzhen 518116, China.}

Received: 10 July 2019 Accepted: 9 December 2019

Published online: 16 December 2019

\section{References}

1. Szajnik M, Czystowskakuźmicz M, Elishaev E, Whiteside TL. Biological markers of prognosis, response to therapy and outcome in ovarian carcinoma. Expert Rev Mol Diagn. 2016;16(8):1.

2. Reid BM, Permuth JB, Sellers TA. Epidemiology of ovarian cancer: a review. Cancer Biol Med. 2017;14(1):9-32.

3. Allemani C, Weir HK, Carreira H, Harewood R, Spika D, Wang XS, Bannon F, Ahn JV, Johnson CJ, Bonaventure A. Global surveillance of cancer survival 1995-2009: analysis of individual data for 25,676,887 patients from 279 population-based registries in 67 countries (CONCORD-2). Lancet. 2015;385(9972):977-1010.

4. Torre LA, Trabert B, Desantis CE, Miller KD, Samimi G, Runowicz CD, Gaudet MM, Jemal A, Siegel RL. Ovarian cancer statistics, 2018. Histopathology. 2018;68(4):284-96.

5. Cortez AJ, Tudrej P, Kujawa KA, Lisowska KM. Advances in ovarian cancer therapy. Cancer Chemother Pharmacol. 2018;81(1):17-38.

6. Yallapu MM, Maher DM, Sundram V, Bell MC, Jaggi M, Chauhan SC. Curcumin induces chemo/radio-sensitization in ovarian cancer cells and curcumin nanoparticles inhibit ovarian cancer cell growth. J Ovarian Res. 2010;3:11

7. Snyder GL, Greenberg S. Effect of anaesthetic technique and other perioperative factors on cancer recurrence. $\mathrm{Br} J$ Anaesth. 2010;105(2):106-15.

8. Chen X, Wu Q, You L, Chen S, Zhu M, Miao C. Propofol attenuates pancreatic cancer malignant potential via inhibition of NMDA receptor. Eur J Pharmacol. 2016:795:150-9.

9. Kvolik S, Glavas-Obrovac L, Bares V, Karner I. Effects of inhalation anesthetics halothane, sevoflurane, and isoflurane on human cell lines. Life Sci. 2005;77(19):2369-83.

10. Kvolik S, Dobrosevic B, Marczi S, Prlic L, Glavas-Obrovac L. Different apoptosis ratios and gene expressions in two human cell lines after sevoflurane anaesthesia. Acta Anaesthesiol Scand. 2010:53(10):1192-9.

11. Yang Y, Hu R, Yan J, Chen Z, Lu Y, Jiang J, Jiang H. Sevoflurane inhibits the malignant potential of head and neck squamous cell carcinoma via activating the hypoxia-inducible factor-1 a signaling pathway in vitro. Int J Mol Med. 2018;41(2):995.

12. Hua L, Gu M, Yang C, Wen X, Zhou Q. Sevoflurane inhibits invasion and migration of lung cancer cells by inactivating the p38 MAPK signaling pathway. J Anesth. 2012;26(3):381-92.

13. Hua L, Cheng XY, Zhang B, Zhen LZ, Ji YZ, Xian JW. Sevoflurane attenuates platelets activation of patients undergoing lung cancer surgery and suppresses platelets-induced invasion of lung cancer cells. J Clin Anesth. 2016:35:304-12

14. Yi W, Li D, Guo Y, Zhang Y, Huang B, Li X. Sevoflurane inhibits the migration and invasion of glioma cells by upregulating microRNA-637. Int J Mol Med. 2016:38(6):1857
15. Hurmath FK, Mittal M, Ramaswamy P, Umamaheswara Rao GS, Dalavaikodihalli NN. Sevoflurane and thiopental preconditioning attenuates the migration and activity of MMP-2 in U87MG glioma cells. Neurochem Int. 2016;94(2):32-8.

16. Zhang D, Zhou X-H, Zhang J, Zhou Y-X, Ying J, Wu G-Q, Qian J-H. Propofol promotes cell apoptosis via inhibiting HOTAIR mediated mTOR pathway in cervical cancer. Biochem Biophys Res Commun. 2015:468:561-7.

17. Guangzhi L, Gong Y, Bin C, Imelda MU, Miao H, Jingfang Z, Bast RC, Sue-Hwa L, Jinsong L. Stanniocalcin 1 and ovarian tumorigenesis. J Natl Cancer Inst. 2010;102(11):812-27.

18. Tavare AN, Perry NJS, Benzonana LL, Masao T, Daqing M. Cancer recurrence after surgery: direct and indirect effects of anesthetic agents. Int J Cancer. 2012;130(6):1237-50.

19. Otto T, Sicinski P. Cell cycle proteins as promising targets in cancer therapy. Nat Rev Cancer. 2017;17(2):93-115.

20. Li X, Peng X, Wang C, Xu N, Xu A, Xu Y, Sadahira T, Araki M, Wada K, Matsuura E. Synergistic effects of the immune checkpoint inhibitor CTLA-4 combined with the growth inhibitor lycorine in a mouse model of renal cell carcinoma. Oncotarget. 2017;8(13):21177-86.

21. Galimuhtasib HU, Diabassaf M, Haddadin MJ. Retraction note to: Quinoxaline 1,4-dioxides induce G2/M cell cycle arrest and apoptosis in human colon cancer cells. Cancer Chemother Pharmacol. 2018;55(4):369.

22. Thi ND, Hwang ES. Effects of black chokeberry extracts on metastasis and cell-cycle arrest in SK-Hep1 human liver cancer cell line. Asian Pac J Trop Biomed. 2018:8(6):285.

23. Sales MS, Roy A, Antony L, Banu SK, Jeyaraman S, Manikkam R. Octyl gallate and gallic acid isolated from Terminalia bellarica regulates normal cell cycle in human breast cancer cell lines. Biomed Pharmacother. 2018;103:1577.

24. Liu J, Yang L, Guo X, Jin G, Wang Q, Lv D, Liu J, Chen Q, Song Q, Li B. Sevoflurane suppresses proliferation by upregulating microRNA-203 in breast cancer cells. Mol Med Rep. 2018;18(1):455-60.

25. Tangutur AD, Kumar D, Krishna KV, Kantevari S. Microtubule targeting agents as cancer chemotherapeutics: an overview of molecular hybrids as stabilising and destabilising agents. Curr Topics Med Chem. 2017:17(22):2523-37.

26. Li N, Yang L, Deng $X$, Sun Y. Effects of isoliquiritigenin on ovarian cancer cells. Oncotargets Ther. 2018:11:1633-42.

27. Huang L. Glaucocalyxin A induces G2/M cell cycle arrest and apoptosis through the PI3K/Akt pathway in human bladder cancer cells. Int J Biol Sci. 2018;14(4):418-26.

28. Hiroshi Y, Tadashi A, Shun-Ai L, Shota T, Peng H, Masami W, Satoru I, Naohisa O, Akira A, Kohji T. N'-[4-(dipropylamino)benzylidene]-2-hydroxybenzohydrazide is a dynamin GTPase inhibitor that suppresses cancer cell migration and invasion by inhibiting actin polymerization. Biochem Biophys Res Commun. 2014;443(2):511-7.

29. Stegeman H, Span PN, Kaanders JHAM, Bussink J. Improving chemoradiation efficacy by PI3-K/AKT inhibition. Cancer Treat Rev. 2014:40(10):1182-91.

30. Manning BD, Toker A. AKT/PKB signaling: navigating the network. Cell. 2017:169(3):381-405.

31. Yang X, Qiang L, Ting L, Zhiping Z, Guanghui W, Dequan Z, Rong D, Cuiling S, Xiao-Kun Z, Haifeng C. U12, a UDCA derivative, acts as an anti-hepatoma drug lead and inhibits the mTOR/S6K1 and cyclin/CDK complex pathways. PLoS ONE. 2014;9(12):e113479.

32. Guo CL, Wang LJ, Zhao Y, Liu H, Li XQ, Jiang B, Luo J, Guo SJ, Wu N, Shi DY. A novel bromophenol derivative BOS-102 induces cell cycle arrest and apoptosis in human A549 lung cancer cells via ROS-mediated PI3K/Akt and the MAPK signaling pathway. Mar Drugs. 2018;16(2):43.

33. Jenny Szu-Chin $P$, Luping $H$, Tatiana $B$, Lianghao L, Yongjie $Y$, Roger $R$, Andy C, Huiming J, Gabriel DM, Qiang T. Stanniocalcin-1 inhibits renal ischemia/reperfusion injury via an AMP-activated protein kinase-dependent pathway. J Am Soc Nephrol. 2015;26(2):364-78.

34. Ohkouchi S, Ono M, Kobayashi M, Hirano T, Tojo Y, Shu H, Ichinose M, Irokawa T, Ogawa H, Kurosawa $H$. Myriad functions of stanniocalcin-1 (STC1) cover multiple therapeutic targets in the complicated pathogenesis of idiopathic pulmonary fibrosis (IPF). Clin Med Insights Circ Respir Pulm Med. 2015;9(Suppl 1):91-6.

35. Koizumi KHM, Ishida H, Ohyama K, Sugiyama H, Naito A, Toda T, Nakazawa $\mathrm{H}$, Nakazawa S. Stanniocalcin 1 prevents cytosolic $\mathrm{Ca}^{2+}$ overload and cell hypercontracture in cardiomyocytes. Circ J. 2007;71(5):796-801. 
36. Peña C, Céspedes MV, Lindh MB, Kiflemariam S, Mezheyeuski A, Edqvist PH, Hägglöf C, Birgisson H, Bojmar L, Jirström K, Sandström P. STC1 expression by cancer-associated fibroblasts drives metastasis of colorectal cancer. Cancer Res. 2013;73(4):1287-97.

37. Pan X, Jiang B, Liu J, Ding J, Li Y, Sun R, Peng L, Qin C, Fang S, Li G. STC1 promotes cell apoptosis via NF-kB phospho-P65 Ser536 in cervical cancer cells. Oncotarget. 2017;8(28):46249-61.

38. Leung CC, Wong CK. Effects of STC1 overexpression on tumorigenicity and metabolism of hepatocellular carcinoma. Oncotarget. 2017;9(6):6852-61.
39. Chang CM, Doherty J, Huschtscha LI, Redvers R, Restall C, Reddel RR, Anderson RL. STC1 expression is associated with tumor growth and metastasis in breast cancer. Clin Exp Metastasis. 2015;32(1):15-27.

\section{Publisher's Note}

Springer Nature remains neutral with regard to jurisdictional claims in published maps and institutional affiliations.
Ready to submit your research? Choose BMC and benefit from:

- fast, convenient online submission

- thorough peer review by experienced researchers in your field

- rapid publication on acceptance

- support for research data, including large and complex data types

- gold Open Access which fosters wider collaboration and increased citations

- maximum visibility for your research: over $100 \mathrm{M}$ website views per year

At BMC, research is always in progress.

Learn more biomedcentral.com/submissions 